\title{
LA ANIMACION EN LAS NUEVAS CIUDADES Y EN LOS GRANDES CONJUNTOS NUEVOS
}

304: 711.417

\section{por \\ Carlos-Enrique Ruiz del Castillo y de Navascués}

Secretario Técnico del Centro de Cooperación Intermunicipal del Instituto de Estudios de Administración Local

Llega a nuestras manos la reciente, aunque tardía edición del Consejo de Europa, relativa al simposio organizado en Reading del 12 al 17 de septiembre de 1976 por su Consejo de Cooperación Cultural, sobre «La animación en las nuevas ciudades y en los grandes conjuntos nuevos" (1).

Suena ya a tópico invocar la actual -y creciente- preocupación popular y de la propia Administración, sea en la esfera estatal, sea en la local, por lo urbanístico entendido en su más amplio sentido. Los encuentros nacionales e internacionales, la profusion de organismos, la especialización en las diversas materias conexas con el urbanismo, el manejo de técnicas propias, la configuración disciplinar de un "Derecho urbanístico" y, aun casi dentro de él, de ramas de creciente importancia y sustantividad como el "Derecho ambiental", con la notable primicia del profesor don Ramón MARTIN MATEO y la cantidad de revistas y libros difusores del quehacer urbanístico, son datos reveladores de la preocupación general que suscita en nuestros días la organización de nuestras ciudades y de la vida en ellas. Este Instituto de Estudios de Administración Local es muestra inequívoca de cuanto queda dicho. Su vocación en este campo queda configurada en su Centro de Estudios Urbanos, con una misión que no por silenciosa deja de ser asumida con

(1) Conseil de la Coopération Culturelle, Conseil de l'Europe. Estrasburgo, 1978. 53.438 (04). 
entrega. La organización de cursos y seminarios, la preparación de diplomados técnicos urbanistas, la elaboración de temarios y de estudios y proyectos urbanísticos corren parejas con una labor editorial importante, que en estos días forma ya con sus títulos sobre la ciencia urbana un importante sector de la citada actividad editorial de esta Casa. Complemento de todo ello es la publicación de la Revista de Ciencia Urbana - Ciudad y Territorio, de alta calidad intrínseca y formal.

En el urbanismo, las técnicas y los medios son hoy aplicados o esgrimidos por realizadores y por opinantes para aprovechar o para poner en tela de juicio las posibilidades de la ingeniería y de la arquitectura, de los juristas y de los sociólogos, en la realización de la ciudad moderna. $Y$ en la evolución, despliegue y reforma de la antigua. Hace ya mucho tiempo que no podemos resignarnos a considerar a la ciudad, que nos devora y nos anula a través de su propio crecimiento, al que contribuimos, como resultado de un simple proceso biológico inexorable. Las leyes que rigen la vida en la ciudad y a la ciudad misma como a cualquier otro organismo participan, en parte, de ese carácter. Pero, en parte también, esas leyes deben ser mediatizadas, corregidas y dotadas de dirección y sentido desvinculadores de un proceso ciego y fatalista que quedaría plenamente posibilitado a través de la más liberal de las concepciones del laissez faire. El hombre no puede quedar aprisionado en su obra y, menos aún, ser anulado por ella. De aquí la necesidad de la gestión urbanística, de la que se desconoce o se olvida allende nuestras fronteras que cabe a España la honra de asumir las primeras aportaciones en este campo, ya en el siglo pasado, mediante las Leyes de Ensanche de 1876 y 1892. Y no nos remontemos a las diversas ordenanzas de nuestros siglos americanos, que con perspectiva en el espacio y en el tiempo fueron regulando los "repartimientos», asentamientos, «reducciones» y demás procesos de . urbanización de todos conocidos.

Ha tenido que llegarse a estas alturas de nuestro siglo para que la actividad más o menos aceptada y siempre compleja de los poderes públicos sufriera los embates del clamor popular. No basta ya que la propia Administración declare sus insuficiencias y sus deficiencias. No hace muchos días, en las III Jornadas sobre Medio Ambiente Urbano, indicaba nuestro Ministro de Obras Públicas y Urbanismo que mejor que hablar de competencias de la Administración para remediar la situación ambiental de las ciudades 
españolas ahabría que empezar a decir incompetencias». Son cinco por lo menos los Ministerios que se ocupan - «y se ocupan mal», admitió el Ministro- del medio ambiente en España. Los medios son insuficientes y el problema es cada día más grave. Los españoles poseen ya una gran preocupación por el medio ambiente, continuó señalando; lo que es preciso ahora es trasladar esa conciencia a la Administración (2).

Así, con el interés de los administrados — de los ciudadanospor la situación, las más de las veces caótica o cuando menos irracional de su ciudad, se ha venido a establecer una interacción que lleva al primer plano de la vida comunitaria la cuestión urbanística y dentro de ésta queda situada como primordial tarea la de la participación, como forma de expresión y afirmación popular ante la Administración y como medio de cooperación con ésta.

Pero las limitaciones inherentes a toda empresa humana se hacen aquí presentes de varios modos y no lo revela con menor importancia el hecho de que en el ejercicio de la participación sean rebasadas las propias posibilidades que ésta ofrece en detrimento de la ecuanimidad de las críticas y de las exigencias, así como del respeto al orden jerárquico en la gestión de la cosa pública. Por una parte, y admite Carrasco Canals (3) que el fenómeno de la conciencia ambiental y su carácter contemporáneo producen $-\mathrm{y}$ aquí está el peligro- reacciones emotivas y protestas indiscriminadas contra el progreso, con aspiraciones al inmovilismo y aún a la vuelta al pasado. Se origina, pues, una distorsión en la óptica con que son percibidos y valorados los problemas urbanísticos, contemplados sin la necesaria serenidad que caracteriza al científico.

Por otra parte, el administrado no debe perder de vista que su participación, generalmente ejercida a través de asociaciones vecinales, no es enfrentamiento sino confrontación, no es suplantación sino cooperación. A esta situación arebelde» de las asociaciones se ha referido recientemente el Alcalde de París, M. Jacques CHIRAC al estimar que aquéllas se encuentran en Francia en una etapa «infantil»: más contestatarias que concertadoras, más folklóri-

(2) Vid. diario El Pals, Madrid, 22-XI-1978, pág. 23, sobre estas III Jornadas celebradas en Madrid del 21 al 24 de noviembre último.

(3) «I Jornadas sobre Medio Ambiente Urbano», celebradas en Madrid del 15 al 19 de noviembre de 1976. Crónica de Carlos Carrasco Canals en esta Revista DE ESTUDIOS DE LA VIDA LOCAL, núm. 192, correspondiente a octubre-diciembre de 1976, páginas 811 y sigs. 
cas que responsables, proclaman con facilidad una cosa y la contraria, lo cual es peligroso. Continuaré tratándolas -añade- porque es preciso proseguir esta concertación pedagógica. $\mathrm{Y}$ espero que en su roce con la realidad se hagan más responsables (4).

En su significado primario cabe aproximar las ideas de participación y de animación. Podrán variar, en principio, los sentidos de una y otra. La primera emana de abajo a arriba y la segunda desciende de la autoridad al administrado. Pero cabe completar la idea con una inversión de esos sentidos: la participación es estímulo, pero a su vez puede ser resultado de otro estímulo. La participación es denuncia de una situación e incitación a que sea corregida; pero es también respuesta de colaboración, sensibilidad ante la animación, cooperación con la gestión urbanística en nuestro caso. Este tema de la animación, tan rico en matices, tan lleno de posibilidades según los medios y los modos de su ejercicio, es el tema básico del encuentro internacional que recoge esta crónica.

En efecto, bajo el patrocinio del Consejo de Cooperación Cultural del Consejo de Europa, tuvo lugar en Reading (Berkshire, Inglaterra), durante los días 12 al 17 de septiembre de 1976, un Simposio Internacional sobre "La animación en las nuevas ciudades y en los grandes conjuntos nuevos". Este forum constituye el último de una serie de cuatro sobre el tema de la animación, de los cuales los tres precedentes han tenido lugar en Rotterdam ("Análisis de los equipamientos de apoyo a una animación sociocultural»), San Remo («Actividades y finalidades de la animación»), y Bruselas ("Condición socioprofesional de los agentes de la animación»).

$\mathrm{Y}$ con este cuatro forum de Reading ha culminado el proyecto de cooperación cultural del Consejo de Europa sobre el desenvolvimiento sociocultural de la comunidad, en palabras de $\mathrm{Mr}$. J. A Simpson, Director de dicho proyecto, extendido a lo largo de cinco años de largos trabajos y de prometedores contactos.

Dos han sido las ponencias elaboradas como base de las comunicaciones y debates: M. Pierre MoulinIER, responsable de los estudios en el Servicio de Estudios de la Secretaría de Estado para la Cultura, en Francia, ha elaborado la primera: "Informe sobre la política de animación en las nuevas ciudades y en los grandes

(4) Vid. en el diario Le Monde, de París, 21-XI-1978, pág. 35, las declaraciones del Alcalde ChIRAC a los periodistas con motivo del abandono, por parte del Consejo Municipal de París, del proyecto de la vía exprés de la margen izquierda del Sena. 
conjuntos nuevos". A G. van Enckevort, Secretario del Comité para la Educación Local de los Adultos, en Holanda, se debe la segunda : «Visión de conjunto y análisis de la práctica de la animación en Europa».

Las comunicaciones aportadas al forum exponen problemas y realizaciones de Suiza, Noruega, Chipre, España, Reino Unido, Suecia, Irlanda, Grecia y Bélgica, y han asistido con carácter de participación activa o de observación delegados de Austria, Bélgica, Chipre, Finlandia, Grecia, Holanda, Irlanda, Italia, Portugal, la República Federal Alemana, el Reino Unido de Gran Bretaña, la Santa Sede, Suecia y Suiza. Y tanto las ponencias como las comunicaciones han sido completadas con visitas de los reunidos a las ciudades británicas de Swindon (en Wiltshire, en el valle del alto Támesis, con 70.000 habitantes) y Basingstoke (en Hampshire, a unos $80 \mathrm{kms}$. al oeste de Londres, con 68.000 habitantes), lo que dio ocasión al mantenimiento de especiales contactos con los Consejos comunitarios de Thamesdown, Eastcott, Groundwell Farms, Cower Shaw Farm y el Departamento de Educación del Consejo del Condado de Wiltshire, así como el Comité Mixto de Desarrollo de la Ciudad y con el Grupo de Desarrollo, ambos referidos a la ciudad de Basingstoke, pensada para absorber el excedente demográfico de Londres.

Un resumen inglés que cita SIMPSON, formulado a través de síntesis del propio SimpSON y de M. HICLER, permite al ponente G. van ENCKEVORT referir la animación a un "estímulo imprimido a la vida mental, física y afectiva de los habitantes de un sector dado, para incitarlos a emprender diversas actividades que contribuyan a su plenitud, para que se realicen mejor y adquieran conciencia de pertenecer a una colectividad sobre cuya evolución puedan influir". Ante la filosofía que expresan estas palabras, que no es otra que la emanada de las reuniones de Rotterdam, San Remo y Bruselas, el ponente efectúa un balance de las virtudes y carencias de la definición, contrastadas a la luz de las realizaciones de la Europa comunitaria.

No es fácil generalizar conclusiones. Ya lo advierte el ponente M. Pierre Moulinier. El mismo sentido de las comunicaciones al simposio aconseja andar por este camino con cautela. Hay, en efecto, realizaciones acabadas que constituyen un logro auténtico: Francia y Gran Bretaña, por ejemplo, pueden aportar datos reales de lo que es una ciudad enteramente nueva. Pero esas nuevas urbes 
proveen en dichas Naciones a un propósito (la absorción de excedentes humanos de grandes concentraciones) muy distinto del que se ha formulado Chipre, por ejemplo, donde la nueva ciudad no está dirigida a esa absorción de excedentes humanos, sino a la implantación pura y simple de poblaciones con un sentido colonizador, no ajeno, acaso, a las tensiones políticas existentes en la isla, según opinamos. En efecto, la diversidad de metas es apreciada por M. Pierre Moulinier al valorar la política impulsora de los asentamientos chipriotas como estimulante del crecimiento urbano y la actividad de la Europa occidental como freno y dominio de ese crecimiento.

El propio concepto de ciudad nueva se interfiere en las diversas aportaciones al forum con el de barriadas nuevas. Así, España aporta la configuración de Moratalaz, en un Madrid no tan periférico ya; aunque cabría haber aludido a alguna realización de absoluta novedad, como es el caso de nuevos poblados de colonización de extensión agraria, pues si bien la magnitud de los problemas urbanísticos, derivada principalmente del asentamiento de excedentes demográficos, no constituye la causa de la organización de esos nuevos poblamientos, no por ello deja de existir la necesidad de una intervención cultural que imprima sentido comunitario y calor humano al nuevo núcleo poblacional, por recoger alguno de los elementos relativos a la animación que han dado lugar, precisamente, al simposio que aquí se comenta.

A ello alude el informe español -con una idea en la que Grecia y Chipre coinciden con nuestra Patria - al asignar a la animación la misión de transmitir una cultura útil. Y ha sido debatida en las reuniones con especial dedicación la posible unificación de una animación cultural y de una animación social o la disociación de ambas ideas. El informe del ponente general Mr. Roy SHAw, Secretario general del Consejo de las Artes de Gran Bretaña, expondrá la idea «que no he escuchado en ninguno de los debates del Consejo de Europa» de que la cultura no siempre tiene una dimension social: puede estar orientada como acción enriquecedora del individuo, no de la comunidad. Dejemos al margen lo discutible de este aserto, pues, en definitiva, parece que todo cambio en los gustos o en la sensibilidad individual introduce, al ser contagiado a otros individuos, un cambio en la comunidad de la que forman parte.

Otro cometido asignado a la animación en el forum es el de permitir la autoexpresión de los miembros de la comunidad. El 
informe británico alude, en este sentido, a la creación de centros donde se advierte que el individuo «cuenta». El animador es un experto en «relaciones humanas» y utiliza métodos no directivos. La comunicación francesa alude, casi en la misma línea, a que la acción cultural no apunta tanto «a la conservación del patrimonio, o a la difusión de las artes", como a "desarrollar la vida social y la participación activa de los habitantes en su propio destino», para lograr un "consentimiento común» que humanice la ciudad.

Más allá van otras ideas sobre la animación, referidas, por ejemplo, a la liberación y a la emancipación del individuo. El propio comunicado francés recoge esta formulación como diametralmente opuesta a la precedentemente aludida. Se trataría, aquí, en expresión del ponente M. MoulinIER, de una animación salvaje que se propone "transformar la sociedad". No es preciso señalar las situaciones en que puede desembocar esta actitud de exaltación tan proclive al descontrol de las conductas.

Los ligerísimos apuntes que preceden enmarcan a la animación como una actividad de promoción: de la cultura, del bienestar, de la condición social, de la ciudad misma, de sus servicios, del hábitat, etc. Bien parta de los gestores del urbanismo o de los «urbanizados»; bien se refiera a las nuevas ciudades, a los nuevos núcleos periféricos de las antiguas o a la remodelación de estas últimas; en cualquier caso, el fin último de la animación es el individuo. Varían las ópticas y por tanto los medios a que se apela, pero todo se concentra en el ciudadano. Desde RousSEAU apenas hay otro dios, al fin y al cabo, en el firmamento humano.

Ello trae de la mano un término tan utilizado en la actualidad y con interpretaciones tan variadas como es el de democracia. Esta es hoy invocada frente a todo ejercicio autoritario personalista del Poder, fórmula ésta denigrada actualmente con fundamento vario. Como lo recordaba hace poco al evocar el juego de palabras de una expresión histórica el Patriarca de Venecia y malogrado Papa JUAN PaBlo I: "La Triple Alianza es la doble, es decir, Bismarck. Parece, por el aire democrático que me llega de vosotros, que los Bismarck, ahora, no gustan demasiado» (5).

El profesor G. T. Fowler, miembro del Parlamento británico y Ministro de Estado encargado del Departamento de Educación y Ciencias, en su alocución, el cuarto día de sesiones, atribuye a la democracia no sólo un contenido constitucional y regulador de sis-

(5) Albino Luciani: Ilustrísimos señores, Cartas del Patriarca de Venecia. Biblioteca de Autores Cristianos, Madrid, 3.' ed., 1978, pág. 118. 
temas representativos, sino también un vigor que dimana de una población activa, comprometida y consciente. Con esa base democrática, la animación, dirá en el simposio el profesor HADLEY, estimula la afirmación y apertura del individuo, incitándolo a asociarse a los negocios de la colectividad y abriendo brecha en las tradiciones de pasividad y de dependencia, que han de quedar sustituidas por la participación y la autodeterminación. $\mathrm{Y}$ acaso para no llegar, por esta vía, a la "animación salvaje» a que se refería M. Pierre Moulinier, el ponente general, Mr. Roy SHAW, añadirá que la democracia nos obliga a pensar que todos los hombres merecen igual consideración y respeto, pero que no obliga a pensar - porque ello es notoriamente falso- que las manifestaciones culturales de los diferentes grupos de la sociedad tienen el mismo valor; expresará a continuación sus temores sobre las palabras de Mr. FOWLER, relativas al aprovechamiento por parte de la masa obrera de "su cultura" y no la de la alta cultura, y ciñéndose a Inglaterra, se pregunta si ha existido verdaderamente una cultura obrera a partir de la revolución industrial. Y no cabía sustraer a la política el problema de la animación, ya que participa de un carácter intrínsecamente político y no meramente instrumental y técnico. Todo en la ciudad es hoy politizado, por lo que no cabe desvincular de tales implicaciones al quehacer urbanístico. Acaba de proclamar el catedrático de Arte, don Antonio BonET, en la preparación del I Simposio Nacional de Urbanismo, organizado por la Universidad Complutense de Madrid, que «se va a tocar el urbanismo, en muchos casos, en relación con el cambio social e incluso político y los elementos que este cambio introduce en la propia vida de la ciudad» (6). No podía ser de otra forma, sobre todo al advertir la temática de la convocatoria: «Permanencia y cambio en las ciudades españolas».

Por lo demás, nos remitimos a la edición del Consejo de Europa relativa al forum a que se contrae esta crónica para que, a través de sus 109 páginas y de los folletos separados en ella aludidos, se pueda profundizar en los temas aquí recogidos por el cronista, que se daría por satisfecho si hubiera logrado prender en el lector el interés por lo tratado en Reading desde ángulos tan diversos y proyectado sobre actitudes tan dispares como las que caben dentro de una consideración sociológica del urbanismo.

(6) Vid. diario El Pals, Madrid, 22-XI-1978, pág. 23. 


\section{REVISTA} $\mathrm{DE}$

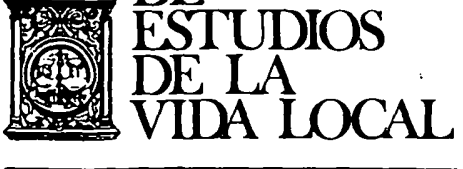

\section{ESTADISTICA}


REVL-1979, núm. 201. RUIZ DEL CASTILL@Q Y DE NAVASCUES, CARLOS-ENRIQUE. LA ANIMAC... REVL-1979, núm. 201. RUIZ DEL CASTILLO Y DE NAVASCUES, CARLOS-ENRIQUE. LA ANIMAC... 